\title{
Fostering study time outside class using gamification strategies: An experimental study at tertiary-level database courses
}

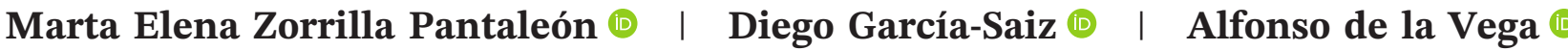

Dpto. Ingeniería Informática y Electrónica, Facultad de Ciencias, Universidad de Cantabria, Santander, Cantabria, Spain

\section{Correspondence}

Marta Elena Zorrilla Pantaleón, Dpto. Ingeniería Informática y Electrónica, Facultad de Ciencias, Universidad de Cantabria, Santander, Avenida de los Castros, s/n, Cantabria 39005, Spain. Email: marta.zorrilla@unican.es

\section{Funding information}

Vicerrectorado de Ordenación Académica y Profesorado Universidad de Cantabria, Grant/Award Number: IV CONVOCATORIA DE PROYECTOS DE INNOVACIÓN DOCENTE

\begin{abstract}
The application of game principles to nongame contexts has proven to be a powerful pedagogical strategy in the educational area to motivate, engage, and improve learners' performance. In this study, gamification is applied to increase the time and the effort that learners spend in carrying out outside-class activities, as well as to modify a quite common study pattern of working at the last minute, that is, near exams or deadlines. Our aim was to motivate students to work weekly on the contents of the subject by carrying out practical exercises that led to a deeper knowledge acquisition, development of skills, and the achievement of the learning outcomes gathered in the subject teaching guide. We describe here the gamification strategies applied to two tertiary database courses in two consecutive academic years, following, in one case, a ranking-based strategy, that is, achieving points by performing different activities; and, in the other one, a strategy based on earning badges and experience points. Next, we analyze the student log activity data along with deadlines and exam information, to assess at what extent gamification helped fulfill our goal. Likewise, we discuss the results of an anonymous survey carried out at the end of the semester to gather the students' opinion. We can conclude that the gamification activities are well appreciated by the learners, especially those that take little time to complete and can be repeated many times to prepare their final exams.
\end{abstract}

\section{K E Y W O R D S}

autonomous learning, databases, engagement, gamified learning, higher education

\section{1 | INTRODUCTION}

The European Higher Education Area ${ }^{1}$ supposed a shift in the teaching-learning process from a teacher-centered method, based on magistral classes, to a more

$1_{\text {https://www.ehea.info/ }}$ participatory student-centered one, focused on the development of skills and the acquisition of knowledge suitable for problem-solving. In this latter method, teachers help students in their learning process by offering support and guidance and by promoting the interaction among peers to construct knowledge in a collaborative and meaningful manner. This shift meant a new organization of the teaching guidelines where, in addition to 
the topics, competencies, and skills to be acquired, the learning outcomes as well as the student's workload have to be explicitly defined. This workload is defined as the estimation of the amount of time a student typically needs to complete all learning activities such as lectures, seminars, projects, labs, work placements, and individual study required to achieve the defined outcomes in formal learning environments [10]. It is commonly established that one ECTS (a learner credit) corresponds to up to $30 \mathrm{~h}$ of student's work distributed in approximately $10 \mathrm{~h}$ of scheduled teacher-contact interventions, whereas the remaining hours correspond to the estimated time that learners should spend in their self-study, completion of the assignments, and exam preparation [22].

The Bologna system has been implemented for 20 years, but we observed that our students do not seem to dedicate the out-of-class hours per week of study estimated in the subject's workload. As a result, some of them are disoriented in the first week and lost in the next ones, which might lead to the undesired drop-out. In general, teachers adapt the workload to the context and level of the subject to fulfill the learning outcomes. However, what is really important is to pay attention to the learner's perceived workload and how this can be lowered if the course design is attractive, the teacher shows enthusiasm and implication, and the requested activities or projects are considered interesting by the students, independently of the associated time investment [16].

Taking into account these premises, and with the aim of fostering study time outside class, we designed a gamification strategy in two university-level database subjects based on giving acknowledgments and awards to students who worked with a regular pattern. This implies that gamification was aimed at fostering extrinsic motivation to the learners to engage them to participate and complete the proposed activities ${ }^{2}$. We followed two different strategies, according to the number of students involved in each subject: (1) the strategy for the Databases course (DB), with around 60 students per year, was based on earning badges and experience points for conducting questionnaires; and (2) for the Information Systems Development subject (ISD), with close to 30 learners per year, the strategy was organized on a leaderboard obtained from the mark of a set of activities that required a higher involvement (labs, design exercises, etc.). This experience was performed twice for each course, precisely, in the 17/18 and 18/19 academic years. The experience developed in the first academic year helped teachers to know the strengths and weaknesses of the

\footnotetext{
$\mathrm{2}_{\text {https://elearningindustry.com/gamification-and-motivation-content-matters }}$
}

applied gamification strategies, which allowed fixing any encountered issues in the following edition of the course. It must be pointed out that this initiative arose as a consequence of the low academic results achieved by learners in one of the subjects, ISD, for several consecutive academic years.

The research questions that we raised at the beginning of this project to assess both experiences were as follows:

- Does gamification favor extrinsic motivation and foster regular study when it is aligned with the short- and medium-term objectives that are to be achieved in the subject?

- What gamification strategy is more attractive for our learners and which one achieves a greater impact on their performance: the first one based on personal rewards or the second one that promotes competitiveness with leaderboards?

- Is it counterproductive to offer extra points in the final grade as a reward or, on the contrary, is this the hook that makes it attractive?

To answer these questions, we analyzed the degree of completion of the requested tasks, when these tasks were completed along the course, and the obtained results. In addition, we collected students' opinion and suggestions of improvement of the gamification activities via an anonymous survey.

The paper is organized in the following sections. Section 2 gives a background on gamification techniques and relates a list of works that served as guide and inspiration to design our strategy. Then, Section 3 describes the subjects under study and the gamification strategy adopted, taking into account the formative contents and the size of the group. In Section 4, strengths and limitations of the experiences are evaluated from a quantitative and qualitative point of view. Finally, our conclusions and future work are outlined in Section 5.

\section{2 | GAMIFICATION}

Gamification has emerged as a powerful technique that can be applied to different problems to influence human behavior. This term was first documented in 2008, but it did not gain momentum in higher education until 2013 [28]. Currently, this domain receives a considerable amount of attention according to the number of published research articles [15]. Gamification is commonly defined as the use of game design elements in nongame contexts [7].

It is important to point out that gamification is not the same field as Game-Based Learning (GBL) or Serious 
Games [1]. GBL is a pedagogical approach consisting of making students explore different parts of specifically crafted games to help them enhance a set of skills or to achieve specific learning outcomes. Relevant studies have indicated that digital GBL possesses significant potential for increasing students' learning motivation and engagement [23] and cultivates their minds and spirits, thus enhancing their learning efficiency [31]. Similarly, Serious Games represent a form of game-based learning and refer to the design of fully-fledged games for nonrecreational environments [30].

There are different strategies to implement gamification. The simplest one is called pointsification [17], which is based on giving rewards to a user based on completing activities and/or on reaching a performance indicator. One of the most used combination of elements of game [26] to implement this strategy is the wellknown Point-Badge-Leaderboard (PBL), which proposes to use three elements with certain synergies between them: points provide feedback and display progress; badges represent achievements; and leaderboards boost competition showing learners where they stand in relation with their peers [14]. Likewise, a more elaborate strategy is denoted overlay, and involves combining a game with actions you do in the real world, so that actions in the real world can have an impact on the game world [26].

According to the literature review on gamification in higher education performed by Subhash and Cudney [28], points, badges, leaderboards, and levels are the most commonly used game elements of the gamification strategies used in real experiments. In general, there are observed benefits in engagement, motivation, and attitudes. However, the so-desired improvement of student performance is observed in some studies, but not in others [24].

The choice of the game strategy to follow must be made according to the objectives to be achieved, the scenario where it is going to be applied, the number of participants, as well as the time and resources available [12]. In addition, we must bear in mind that the game mechanics can motivate some users, but not others [21]. Therefore, the gamification strategy should include mechanics associated with different player typologies, if possible. Designing games is a far from trivial task, involving complex and multifaceted issues that require an understanding of (motivational) psychology [15]. Consequently, it is convenient to rely on a gamification framework to define and deploy any selected strategy in a systematic and well-studied manner. As described by Mora et al. [20], there are several gamification design frameworks available to apply. In our experiments, we relied on two general-purpose frameworks that provide various use cases on their web pages and books: the Game framework proposed by Marczewski [18] and the Octalysis framework designed by Chou [14]. Authors used both frameworks because when they were designing the strategy, they understood that each proposal was better adapted or explained in one of them.

Game [18] is based on two phases: planning and designing. In the planning phase, three questions must be answered: (1) what is being gamified? (2) why is it being gamified? (what do you hope to gain from this project?), and (3) who are the users? Then, in the designing stage, we must think about what game elements and rewards will be used, including the analysis that will be performed to monitor different indicators during the activity, such as users' engagement.

Octalysis [14] established four phases to organize the user's journey: discovery, onboard, scaffolding, and endgame. First, the players investigate the reason why they should play the game and establish an attitude toward it. Next, players familiarize with the game by completing the first tasks and learning the basic mechanics. The scaffolding phase starts once a player has learned the rules to play the game and has achieved a certain level. Finally, the endgame stage must keep players' motivation by making them apply the acquired knowledge and skills in challenging tasks.

Apart from following a gamification design framework, it is also useful to utilize design patterns [11,29], which let us exploit the accumulated experience from previous implementations. To enumerate a few, Mora et al. [19] designed a gamification strategy based on the achievement of points and awards in collaborative activities under the metaphor of an Agile environment under the SPARC framework (https://sparcopen.org/). Cosentino et al. [5] developed a generic model-based approach for gamifying the learning of modeling and applied it to UML learning. Jurgelaitis et al. [13] implemented gamification in a university-level UML modeling course in Moodle using points, leaderboard, content locking, and trading. Many more references can be found in recently published surveys such as [28] and [1]. It must be highlighted that, to the best of authors' knowledge, this paper is the first one that applies game strategies to database topics.

\section{3 | GAMIFYING DATABASE COURSES}

We performed the gamification experiments described in this section in the Computer Science degree of the University of $<$ province $>(<$ country $>)$. This degree includes three subjects related to database topics $[9,27]$. The first 
one, Databases (DB), mainly addresses general concepts in relational database design and intermediate SQL language (around $50 \mathrm{~h}$ ), and some extra concepts in security and application development $(10 \mathrm{~h})$. This subject is taught in the fourth term of the degree and is compulsory. Approximately, 60 students enroll each academic year. The second subject, Information Systems Development (ISD), is a noncompulsory subject located in the sixth term with around 30 learners per course. The topics include UML/ER conceptual modeling, logical and physical modeling for both relational and dimensional databases, administration, security, testing, and the use of persistence layers. The last subject is also optional, and it gathers advanced database topics and is chosen by around 10 learners in each course. This third subject was not part of our gamification experiments.

It is important to remark that the academic guide and the evaluation of these subjects were the same in the three academic years under study. This evaluation consisted of three exams distributed throughout the semester, two theoretical tests and one laboratory practical one with a total weight of 55\%, and of the delivery of a team-based or individual project in which they carry out all the phases of the design of a database, from the capture of requirements, passing through the conceptual, logical and physical design until its deployment (15\%). Finally, both have a final exam with a weight of $30 \%$. Therefore, we conclude that the differences in performance are due to both gamified activities and student cohort (see Section 4).

\section{1 | Method for gamifying the databases subject}

This subject was gamified following the Game framework [18]. As commented in the previous section, this is a simple framework composed of two phases. The first one is the planning phase, which involves answering a set of predefined questions. These questions, along with our answers, are the following:

\section{What is being gamified?}

The out-of-class activities performed by the learners during the term. These activities are additional and noncompulsory over those requested during the course.

2. Why is it being gamified?

To motivate students to work more progressively throughout the subject's duration, instead of adopting the typical strategy of only studying before any graded test.
3. What do you hope to gain from this project?

We expect to see a participation of a large proportion of the learners in these activities and an increase of the subject's performance as a consequence of that participation.

4. Who are the users?

Students enrolled in the Databases subject who voluntarily want to participate.

In the second phase, that is, the design of the activities, we defined the game elements and rewards to be used, the metrics to evaluate the success of the gamification, and the schedule of activities during the experiment. Regarding the gamification, teachers opted for an automated method based exclusively on badges for the first edition of these experiments (17/18 academic year), as the number of the students in the group was over 60 and this experience was taking place at the same time as DSI gamification whose strategy required a considerable workload for lectures. Course contents were organized in the following five categories: basic concepts, relational design, basic SQL, intermediate SQL, and other database concepts. For each category, students could earn a badge of either gold, silver, or bronze, depending on their performance in the carried out activities. These activities were composed of a set of tests that were opened in Moodle on certain dates (see schedule in Figure 1, top). Badges expired, which means that it was pursued that the quizzes were carried out when the topic was being studied, leaving two extra weeks for its completion. Each badge comprised two quizzes, one included more conceptual questions and the other one was focused on practical issues. Each gold, silver, and bronze badge granted $0.2,0.15$, and 0.1 points, respectively, up to a maximum of one point. This point was added to the final mark of the student in the subject, but only if the student had passed the subject by itself, that is, scoring 5 out of the 10 points belonging to traditional and compulsory graded items.

After the evaluation of this first experience and, as a consequence of the suggestions received from the learners, new and different types of activities were included for the 18-19 academic year, such as crosswords, term definitions, and SQL competitions. Furthermore, we included the possibility of not only earning points by the obtained mark in the activities, but also by simply participating in them. Precisely, the gamification for this second edition of the Databases course was divided in three items:

- Earning experience points by conducting any gamification activities published in Moodle. The performance of these activities was not taken into account 


\begin{tabular}{|c|c|c|c|c|c|c|c|c|c|c|c|c|c|c|c|}
\hline 2017-18 & & & & & & & & & & & & & & & \\
\hline Activity\Week & 1 & 2 & 3 & 4 & 5 & 6 & 7 & 8 & 9 & 10 & 11 & 12 & 13 & 14 & 15 \\
\hline Badge 1 & & & & & & & & & & & & & & & \\
\hline Badge 2 & & & & & & & & & & & & & & & \\
\hline Badge 3 & & & & & & & & & & & & & & & \\
\hline Badge 4 & & & & & & & & & & & & & & & \\
\hline Badge 5 & & & & & & & & & & & & & & & \\
\hline 2018-19 & & & & & & & & & & & & & & & \\
\hline Activity\Week & 1 & 2 & 3 & 4 & 5 & 6 & 7 & 8 & 9 & 10 & 11 & 12 & 13 & 14 & 15 \\
\hline Quizzes & & & & & & & & & & & & & & & \\
\hline Badges & & & & & & & & & & & & & & & \\
\hline SQL Competition & & & & & & & & & & & & & & & \\
\hline
\end{tabular}

F I G U RE 1 Activities in the DB subject. Top: Activities and weeks when they remained opened during the 2017-2018 course. Bottom: activity types and weeks where one of these activities was made available in the 2018-2019 academic year

for this item, and the experience earned contributed in increasing the level of the students, who were ordered in a ranking.

- Three badges (DB concepts, Basic SQL, Intermediate SQL). These badges were similar to the ones presented in the 17/18 edition: students had to respond to a randomized questionnaire extracted from a pool of questions, and they obtained one or other type of badge depending on their grade.

- The participation and performance in an SQL competition were managed by an external university.

With the aim of not overwhelming the learners, each week only involved a gamified activity, as it can be observed in the schedule at the bottom of Figure 1. Quizzes and badges were deployed in Moodle, whereas the SQL competition was developed with the QueryCompetition [6] tool. This last activity was performed in two rounds during two consecutive weekends, where they had to write four SQL queries per round with an increasing level of difficulty.

The reward for the gamification in this second edition was up to 2 points of the final grade ( $20 \%$ of the mark), in response to the previous year students' suggestion. It is worth mentioning that to pass the subject, the students have to obtain at least 4.5 points over 10 , without taking into account the gamification points, and at least 5 after adding the gamification grade.

The two gamification points were distributed between the different activities as follows:

- Participation (40\%): 15 experience levels, composed of 1000 points per level. Quiz completed: 1000 points. Quiz repeated (only once per quiz): 500 points. Badge completed: 1700 points.

- Badges (30\%): Maximum marks: 90 points; Golden badge: 30 points; Silver badge: 20 points; Bronze badge: 10 points.
- SQL Competition (30\%): Maximum marks: 200 points $-25 \%$ came from participation, whereas $75 \%$ resulted from answering properly the proposed SQL queries (25 points each).

For the participation aspect, learners could observe their experience points earned and the level reached in a web page (see Figure 2) that was upgraded each week.

The gamification project was announced to the students in the first class of the subject and by means of a forum message. All the information about the project and the gamified activities was hosted in a section of the Moodle course. The number of teachers who participated in the experience was three, the lecturer in charge of the subject and two laboratory assistants.

\section{2 | Method for gamifying the information systems development subject}

This subject was gamified following a leaderboard-based strategy. We used a simplified version of the framework proposed by Chou [14] for its design. We pursued the same goal as in the Databases subject, that is, to increase the time involved in studying and practising out of class. This goal was specially important for this subject due to its low pass rate. The topics of this subject are demanding, including conceptual, logical, and physical design of relational and multidimensional databases. Moreover, advanced SQL and application aspects are also included, such as query profiling, transaction management, use of procedures and triggers, and lastly, the programming and testing of persistence layers. In short, the subject requires learners to work weekly to acquire and master these contents.

According to Chou's framework [14], we planned four stages: discovery, onboard, scaffolding, and endgame. 


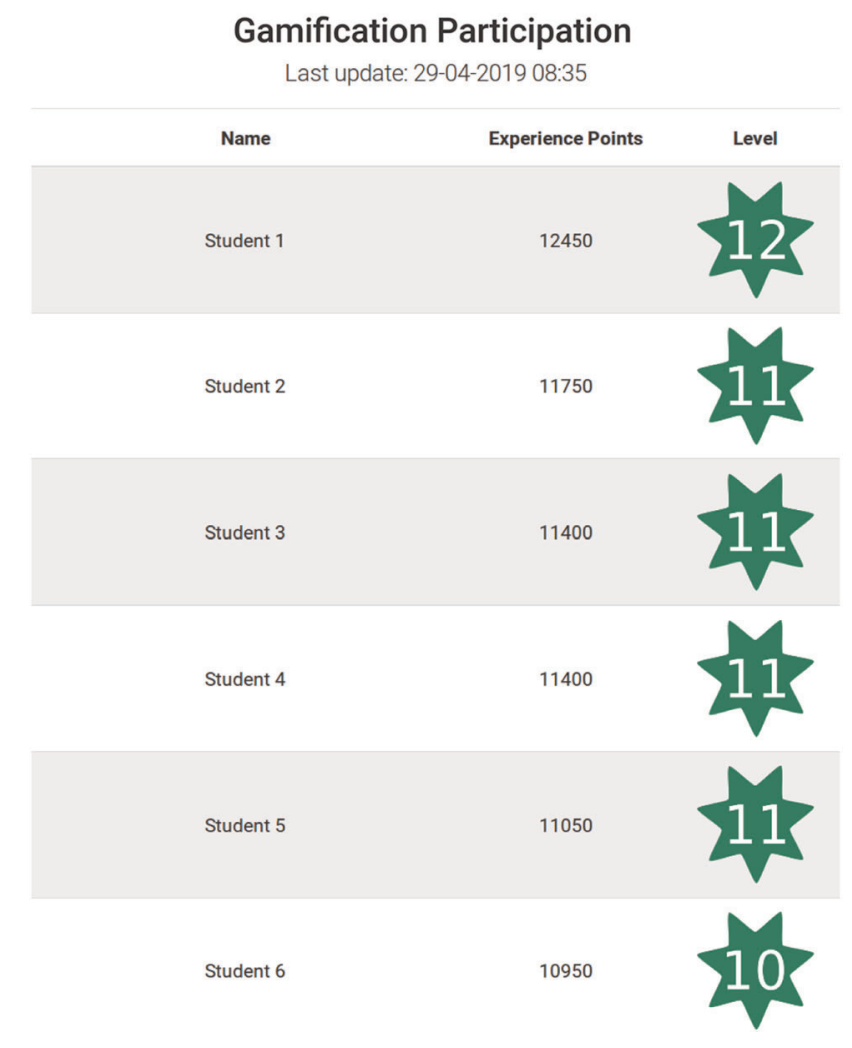

FIGURE 2 Experience points and level ranking

With the aim of making the gamification attractive and engaging learners to participate, sometimes these activities are related to a concrete topic from the real world, such as some sort of race or adventure. In the gamification field, these topics are denoted as epics. In our case, we used as epic a cycling tour, where the students were participants and earned kilometers for the different races of the competition.

The discovery phase was performed the first day of class. Lecturer in charge of the subject described the students the goals and benefits that gamified activities could provide them. Furthermore, a poster was created and published in Moodle to announce the activity and a message was also sent via the subject's forum. Students who wanted to participate (the activity was voluntary) were requested to send an avatar and a nickname.

Next, the game rules were explained. Each gamification activity rightly done granted a number of kilometers in one of the races of the cycling tour. There was a race per each lab practice, which took place weekly. Furthermore, it was possible to get extra points in these races by performing other activities, such as answering questions in class, delivering optional design exercises, or participating in Kahoot challenges or the SQL competition, which were generally announced in class and on the forum. Depending on the difficulty of the activity, more or fewer kilometers could be achieved. Also, any malpractice detected during the gamification activities (e.g., plagiarism, submissions of badly made exercises to get some points with no effort) could involve losing some kilometers, which could be translated to suffering a problem during the race in our cycling epic. Each activity could be carried out only during a concrete period of the course. Labs would be delivered fortnightly and these would be decoupled from the deadline of the rest of activities.

After the discovery phase, the onboard stage was developed during the first week of the course. This consisted of carrying out the first Kahoot challenge and providing the laboratory sheet where students could read gamification rules and how to proceed to earn kilometers. During this week, learners had the opportunity to observe and get familiar with the mechanics of the game. After the first deadline, the initial leaderboard was published in Moodle and participants could see the points achieved in each activity and globally.

The gamification activities continued with the scaffolding stage. New activities were proposed and notified by means of a forum message, in which the lecturer responsible for the subject added sentences of encouragement to keep the gamification active. The teacher also reinforced the benefits that gamification activities provided them and gave clues to those who needed them during the master classes.

The endgame stage lightly overlaps with the previous one, as the feedback and rewards were provided from the beginning. During this stage, we relaxed the demand to maintain interest and reward their effort, and declared that those who covered $80 \%$ of the kilometers of the cycling tour achieved an extra point in the subject (two points in the second edition) and the rest received a proportional value to the kilometers they had pedaled.

The leaderboard was built by means of a spreadsheet (see Figure 3). The gamified activities with the kilometers granted in each academic course are shown in Table 1. Three teachers were involved in this subject, similar to the Databases subject.

\section{4 | DATA ANALYSIS AND EXPERIMENT RESULTS}

As it was mentioned in the introduction section, our goal was to increase the activity performed by learners out of class. To assess the strengths and limitations of the pedagogic experiences designed, we raised several questions and used different instruments to measure the results of both experiences. In particular, we used log data registered in the TIC tools (Kahoot, QueryCompetition, Moodle) to check the degree of achievement of the tasks requested; the period of completion of the tasks; the 


\begin{tabular}{|c|c|c|c|c|c|c|c|c|c|c|c|c|c|c|c|c|}
\hline & $\begin{array}{l}\text { Max. } \\
\text { Kms. }\end{array}$ & 200 & 85 & 30 & 30 & 95 & 30 & 105 & 10 & 75 & 80 & 80 & 180 & 10 & 80 & 1090 \\
\hline \multirow[t]{29}{*}{$\begin{array}{c}\text { color } \\
\text { maillot }\end{array}$} & NICK & Kahoot\# & lab\#1 & lesign\# & lesign\#: & lab\#2 & lesign\#. & lab\#3 & ahoot\#: & lab\#4 & lab\#5 & lab\#6 & RueryCom & kahoot\#3 & lab\#7 & TOTAL \\
\hline & franky & 120 & 100 & & 15 & 65 & & 105 & & - & & - & & & & 405 \\
\hline & sia & & 45 & & 10 & 65 & & 65 & 7 & 45 & 30 & 20 & & 10 & 25 & 322 \\
\hline & nandini & 160 & 115 & & 25 & 15 & & 60 & & 35 & & - & & & & $=410$ \\
\hline & MANU1 & 150 & 100 & & 15 & 95 & 10 & 70 & & 40 & & 20 & 110 & 7 & 50 & 667 \\
\hline & CMA & & & & & & & 30 & 10 & 30 & 30 & 40 & & 10 & 50 & 200 \\
\hline & FAR & & 95 & & 15 & 65 & & 30 & & 25 & & 20 & & & 35 & 285 \\
\hline & charlie & & 75 & & & 0 & & 30 & 8 & 30 & & - & & & 45 & 188 \\
\hline & imanux & 110 & 95 & & 10 & 95 & & 60 & & 45 & & 40 & & & 45 & 5500 \\
\hline & maniace & 140 & 115 & & 15 & 0 & & 40 & & 50 & 30 & - & & & 40 & $=430$ \\
\hline & dopico & 130 & 100 & & 15 & 50 & & 40 & 7 & 30 & & 50 & & & 35 & 5457 \\
\hline & $\mathrm{HMH}$ & & 95 & & 15 & 65 & & 40 & & 30 & & 30 & & & 45 & 320 \\
\hline & jeda & & & & & & & - & & - & & - & & & & $\sqrt{40}$ \\
\hline & & & & & & & & - & & - & & - & & & & 40 \\
\hline & daniel & & 60 & & 20 & 0 & & 40 & & 35 & & 20 & & & 30 & 205 \\
\hline & & & 115 & & & 0 & & 75 & & 55 & & 20 & & & 15 & 280 \\
\hline & & & & & & 95 & & 55 & & 30 & & - & & & & 180 \\
\hline & Harry & & 115 & & & 65 & & 65 & & - & & 30 & & & 35 & 310 \\
\hline & PABLO & 160 & 115 & 20 & 15 & 15 & 10 & 30 & & 40 & & 30 & 30 & 10 & 40 & 7515 \\
\hline & OLE & & & & 20 & 50 & & 30 & 5 & 15 & & - & & 7 & & $\sqrt{127}$ \\
\hline & victorpa & 140 & & & & & & - & & - & & - & & & & $\sqrt{140}$ \\
\hline & & & 115 & & 15 & 0 & & - & & 45 & & - & & & & 175 \\
\hline & pablinR & 120 & 115 & & & 95 & & 60 & & 30 & 30 & 45 & & 6 & 45 & 5546 \\
\hline & & & 75 & & & & & - & & - & & - & & & & $\sqrt{75}$ \\
\hline & Brian8s & 160 & 135 & 20 & 15 & 95 & 20 & 105 & 8 & 75 & 30 & 60 & 55 & 9 & 35 & 822 \\
\hline & SGL & & 80 & & & 15 & & 0 & 4 & 30 & & 0 & & & & $\sqrt{129}$ \\
\hline & IRE & 170 & 95 & & 25 & & 20 & 45 & & - & & - & & 4 & & $\Sigma 359$ \\
\hline & YU & 140 & 45 & & 15 & 65 & 10 & - & & - & & - & & & & 275 \\
\hline & zalaca & 110 & 100 & & 20 & 50 & & 45 & & 45 & & 10 & & & 35 & 5415 \\
\hline
\end{tabular}

F I G U R E 3 ISD Leaderboard in the 2018-2019 academic year. Rows without nick are students who were not interested in participating in the gamification initially, but who later delivered some activities

TABLE 1 Gamified activities in ISD in the 2017/2018 and 2018/2019 academic years

\begin{tabular}{|ll|}
\hline Activities 2017-2018 & $\mathbf{K m}$ \\
\hline 11 Labs & $30-50 \mathrm{~km}$ each lab \\
\hline 3 Kahoots & $1 \mathrm{~km}$ per question \\
\hline 1 Relational design & $15-50 \mathrm{~km}$ each model \\
\hline 1 Discussion paper & $10 \mathrm{~km}$ per question \\
\hline Activities 2018-2019 & $\mathbf{K m}$ \\
\hline 7 Labs & $75-90 \mathrm{~km}$ each lab \\
\hline 3 Kahoots & $1 \mathrm{~km}$ per question \\
\hline 3 Conceptual designs & $30 \mathrm{~km}$ each model \\
\hline Query Competition & $40 \mathrm{~km}$ per question \\
\hline
\end{tabular}

results obtained; and lastly, a survey to gather the students' opinion about the activities.

\section{1 | Database subject analysis}

The number of students enrolled in the database subject in the 2017/18 academic year was 62 , of which ten were in their second enrollment. In this edition, the gamification was exclusively based on badges. Table 2 gathers the participation rate and the number of badges of each type achieved by the learners. The table shows a high participation rate at the beginning of the course, but as a consequence of the fact that the students had to pass two tests per badge with a minimum performance in both, few of them became unmotivated and stopped participating.

In the 2018/2019 academic year, the number of students enrolled in the database subject was 65 , of which 7 were in their second enrollment and 3 dropped out before the course started. Here, the number and kind of gamified activities were extended with weekly quizzes and an SQL competition, and the number of badges was reduced and based on only one test to diversify the activities and attract more students. In the following, we show the participation for each type of activity.

We gathered the participation ratio and the number of students who participated in quizzes in the week that were opened as well as those who repeated them again during the term in Table 3. As it can be observed, the global participation is quite high. Furthermore, the fact that quizzes were kept open during the rest of the course helped learners check their knowledge before exams.

Regarding badges, we can say that this type of activity motivates students, as their participation is quite high, near $80 \%$, as shown in Table 4.

Regrettably, the SQL competition did not have much acceptance. It could be a consequence of the date in 


\begin{tabular}{llllll} 
Badge & Gold & Silver & Bronze & No badges & Participation rate \\
\hline Basic concepts & 16 & 8 & 5 & 17 & $74.19 \%$ \\
Design & 2 & 14 & 8 & 35 & $95.16 \%$ \\
\hline Basic SQL & 6 & 13 & 10 & 10 & $62.90 \%$ \\
\hline Intermediate SQL & 3 & 13 & 11 & 8 & $56.45 \%$ \\
\hline Other DB concepts & 7 & 14 & 6 & 2 & $46.77 \%$ \\
\hline
\end{tabular}

TABLE 2 Badges earned and participation rate in DB in the 2017/18 academic year
TA B LE 3 Number of learners who participated (or not) in each weekly quiz in DB subject in the 2018/19 academic year

\begin{tabular}{|c|c|c|c|c|}
\hline Quiz & $\begin{array}{l}\text { No. } \\
\text { learners } \\
\text { NOT } \\
\text { performed }\end{array}$ & $\begin{array}{l}\text { No. } \\
\text { learners } \\
\text { once }\end{array}$ & $\begin{array}{l}\text { No. } \\
\text { learners } \\
\text { twice } \\
\text { or more }\end{array}$ & $\begin{array}{l}\text { Participation } \\
\text { rate }\end{array}$ \\
\hline 1 & 5 & 40 & 17 & $91.94 \%$ \\
\hline 2 & 11 & 16 & 35 & $82.26 \%$ \\
\hline 3 & 11 & 15 & 36 & $82.26 \%$ \\
\hline 4 & 11 & 12 & 39 & $82.26 \%$ \\
\hline 5 & 10 & 6 & 46 & $83.87 \%$ \\
\hline 6 & 10 & 29 & 23 & $83.87 \%$ \\
\hline 7 & 10 & 18 & 34 & $83.87 \%$ \\
\hline 8 & 11 & 12 & 39 & $82.26 \%$ \\
\hline 9 & 11 & 12 & 39 & $82.26 \%$ \\
\hline 10 & 15 & 20 & 27 & $75.81 \%$ \\
\hline
\end{tabular}

which it was held, 3 weeks before the end of the course, as learners had to complete assignments and prepare exams. It is also true that this activity could not be moved to another date because the students had not acquired the knowledge needed to solve the queries. Although 34 students were initially enrolled, being 22 from DB and 12 from ISD, only 16 students finally participated, 12 from DB and 4 from ISD. Figure 4 collects the results of this activity. It is remarkable that students who performed the best belonged to the Databases subject, despite having to overcome queries whose solution had not been taught in class.

Finally, we analyzed, for the 2018/2019 course, if the gamification points and the final mark are correlated. To

\begin{tabular}{|c|c|c|c|c|c|c|c|c|c|}
\hline 은 & 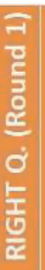 & 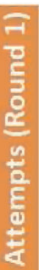 & 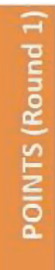 & 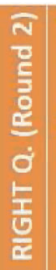 & 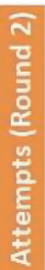 & 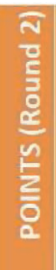 & 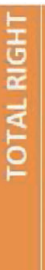 & 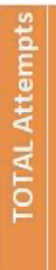 & 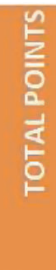 \\
\hline$\cdot$ & 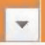 & $\checkmark$ & $\checkmark$ & $\checkmark$ & 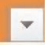 & $\cdot$ & $v$ & $\nabla$ & $\checkmark$ \\
\hline 28431 & 4 & 4 & 100 & 3 & 4 & 80 & 7 & 8 & 180 \\
\hline 28885 & 3 & 4 & 80 & 4 & 4 & 100 & 7 & 8 & 180 \\
\hline 13131 & 3 & 4 & 80 & 3 & 4 & 85 & 6 & 8 & 165 \\
\hline 24258 & 4 & 4 & 110 & & & & 4 & 4 & 110 \\
\hline 28484 & 3 & 4 & 85 & 1 & 4 & 25 & 4 & 8 & 110 \\
\hline 22222 & 1 & 4 & 25 & 3 & 4 & 85 & 4 & 8 & 110 \\
\hline 28348 & 3 & 4 & 80 & 1 & 4 & 25 & 4 & 8 & 105 \\
\hline 29029 & 3 & 4 & 75 & 1 & 4 & 25 & 4 & 8 & 100 \\
\hline 29022 & 2 & 4 & 60 & 1 & 4 & 30 & 3 & 8 & 90 \\
\hline 24475 & 2 & 4 & 55 & 1 & 4 & 25 & 3 & 8 & 80 \\
\hline 29026 & 2 & 4 & 55 & 1 & 4 & 25 & 3 & 8 & 80 \\
\hline 23992 & 1 & 4 & 25 & 1 & 4 & 30 & 2 & 8 & 55 \\
\hline 28704 & 1 & 4 & 25 & 1 & 4 & 25 & 2 & 8 & 50 \\
\hline 6685 & 1 & 4 & 30 & & & & 1 & 4 & 30 \\
\hline 28295 & 1 & 4 & 25 & & & & 1 & 4 & 25 \\
\hline 24498 & 0 & 4 & 0 & & & & 0 & 4 & 0 \\
\hline 24905 & 0 & 1 & 0 & & & & 0 & 1 & 0 \\
\hline 28825 & & & & 0 & 4 & 0 & 0 & 4 & 0 \\
\hline
\end{tabular}

FI G URE 4 Participation and performance in the SQL competition

do this, we show a scatter plot with the points achieved in the subject (10-point grading scale) and the points earned in the gamification (2-point grading scale). As it can be seen in Figure 5, the higher the gamification activity, the higher is the final mark. The Pearson correlation coefficient is 0.73 , which confirms this direct relationship between the mark and the gamification.

\begin{tabular}{llllll|} 
Badge & Gold & Silver & Bronze & No badge & Participation \\
\hline Basic concepts & 24 & 18 & 4 & 2 & $79 \%$ \\
\hline Basic SQL & 26 & 19 & 4 & 2 & $83 \%$ \\
\hline Intermediate SQL & 41 & 9 & 0 & 0 & $80 \%$ \\
\hline
\end{tabular}

T A B LE 4 Badges achieved from quizzes and participation rate in $\mathrm{DB}$ subject in the 2018-2019 academic year 
Final mark vs Gamification points (DB)

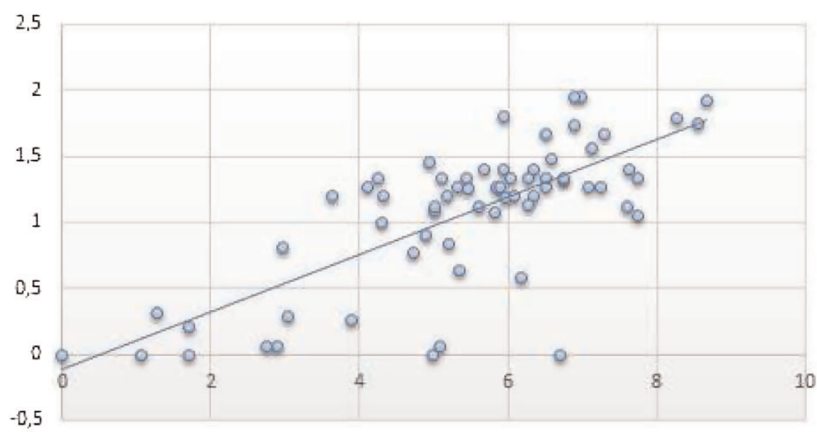

F I G URE 5 Dispersion diagram showing the correlation between the gamification points and the final grade in the Database subject in the 2018/2019 academic year

We performed a $t$-test statistical significance analysis to verify the statement that the participation of the gamification activities has a positive impact in the students' mark. To do so, we divided the students in two groups. One of these groups corresponds to the students who achieved at least a $50 \%$ of the gamification points and the other group was composed of the students who did not achieve them. The first group of students had an average mark of 4.9 out of 10 (standard deviation of 1.1), and the second had an average mark of 3.26 out of 10 (standard deviation of 1.8). The t-test returned a p-value of 0.002 , meaning that the average mark of the two groups is significantly different. Also, the percentage of passed students in the first group of the learners was $89.36 \%$ and it was $33.33 \%$ in the second group, which reinforces this conclusion.

Next, we performed a clustering analysis by using the k-means algorithm with the aim of categorizing our students with respect to their engagement in the gamification activities and their marks. Results are shown in Table 5, where the \% of students row indicates the percentage of students who belong to the cluster; participation, badges, and competition rows show the score obtained by the students in the three gamification activities, respectively, ranging from 0 (no activity) to 1 (maximum score); total row shows the total score obtained in the gamification also ranging from 0 to 1 ; and mark row indicates the final marks achieved by the students in the course. The last column shows the average value of each row for all the students.

The profiles obtained match with four of the six profiles described by [3]: Achievers (Cluster_3), characterized by a larger experience points accumulation and a performance above the average; Regular students (Cluster_2), who participated regularly and with a performance higher than the average; Disheartened students (Cluster_4), who participated a bit and their performance levels are between those of the Achievers and the Underachievers; and Underachievers (Cluster_1), those who started gamification, but finally dropped out and thus failed the subject. The first immediate conclusion extracted from this clustering analysis is that, as commented before, the final mark is quite related to the gamification engagement: the highest qualifications are obtained by students who became more involved in gamification. It can be also observed that the participation in the quizzes (participation row) is the highest for students in Cluster_2, Cluster_3, and Cluster_4. The difference is found in the other two activities, badges and competition, where Achievers students (Cluster_3) have a significant higher activity than the students of the other clusters.

\section{2 | Information system development analysis}

Next, we analyzed the gamification results in the Information Systems Development subject. Tables 6 and 7 collect the number of students who participated in each activity as well as the participation rate in the 2017/2018 and 2018/2019 academic years, respectively. In the first edition of the course, the number of students enrolled was 30, of whom 25 participated in the gamification; in the second edition, 27 out of 28 learners carried out some activities.

As it can be observed, the degree of participation in each activity is very uneven, with the laboratories being
TA B LE 5 K-means clustering performed with the points achieved in gamified activities and the final mark in DB subject in the 2018/2019 academic year

\begin{tabular}{|c|c|c|c|c|c|}
\hline $\begin{array}{l}\text { Cluster } \\
\% \text { of students }\end{array}$ & $\begin{array}{l}\text { Cluster_1 } \\
18\end{array}$ & $\begin{array}{l}\text { Cluster_2 } \\
53\end{array}$ & $\begin{array}{l}\text { Cluster_3 } \\
18\end{array}$ & $\begin{array}{l}\text { Cluster_4 } \\
11\end{array}$ & Average \\
\hline Participation & 0.14 & 0,97 & 0,99 & 0.94 & 0.83 \\
\hline Badges & 0.13 & 0,79 & 0,91 & 0,32 & 0.64 \\
\hline Competition & 0.00 & 0,02 & 0,73 & 0,039 & 0.14 \\
\hline Total & 0.1 & 0,65 & 0,895 & 0,49 & 0.58 \\
\hline Mark & 3.83 & 6.85 & 8,69 & 4,37 & 6.36 \\
\hline
\end{tabular}


TA B LE 6 Gamified activities in the 2017/2018 ISD subject in their requested order, with the number of learners who participated in them

\begin{tabular}{|lll|}
\hline Activity & Participants & Participation rate \\
\hline Kahoot-1 & 14 & $51.85 \%$ \\
\hline Lab-1 & 20 & $74.07 \%$ \\
\hline Lab-2 & 15 & $55.56 \%$ \\
\hline Lab-3 & 15 & $55.56 \%$ \\
\hline Lab-4 & 16 & $59.26 \%$ \\
\hline Lab-5 & 12 & $44.44 \%$ \\
\hline Lab-6 & 12 & $44.44 \%$ \\
\hline Lab-7 & 6 & $22.22 \%$ \\
\hline Kahoot-2 & 16 & $59.26 \%$ \\
\hline Design-1 & 15 & $55.56 \%$ \\
\hline Lab-8 & 3 & $11.11 \%$ \\
\hline Discussion & 12 & $44.44 \%$ \\
\hline Lab-9 & 12 & $44.44 \%$ \\
\hline Lab-10 & 5 & $18.52 \%$ \\
\hline Kahoot-3 & 8 & $25.93 \%$ \\
\hline Lab-11 & 7 & $29.63 \%$ \\
\hline
\end{tabular}

the activity in which learners participated the most. This was expected, as they needed to acquire the skills and competencies required to pass the SQL exam. These also contributed with a greater number of points $(\mathrm{kms})$. It can be noted that the change in the periodicity of delivery of the labs as well as the increase in the points earned by participating in the gamification have contributed to increase the participation rate.

It is worth noting that despite the short time required to answer the Kahoot challenges, only half of the students participated in them. This happened because almost $50 \%$ of the learners did not regularly attend the magistral classes, either due to attending other lectures or due to being employed in a company, thus forgetting delivery dates. The participation rate in both academic years is quite similar. The same effect manifested in the database design activities.

During 2018/2019, an SQL competition was proposed with the aim of attracting Achievers, but, as mentioned in the previous section, only four students participated and with a lower performance than their second course counterparts.

To analyze the correlation between the score achieved by continuous evaluation and the score of the gamification activities (see Figure 6), we built a dispersion diagram with the information from the second
TA B LE 7 Gamified activities in the 2018/2019 ISD subject in their requested order, with the number of learners who participated in them

\begin{tabular}{|lll|}
\hline Activity & Participants & Participation rate \\
\hline Kahoot-1 & 13 & $48.0 \%$ \\
\hline Lab-1 & 22 & $81.0 \%$ \\
\hline Design-1 & 2 & $0.7 \%$ \\
\hline Design-2 & 17 & $63.0 \%$ \\
\hline Lab-2 & 22 & $81.0 \%$ \\
\hline Design-3 & 5 & $1.8 \%$ \\
\hline Lab-3 & 22 & $81.0 \%$ \\
\hline Kahoot-2 & 7 & $26.0 \%$ \\
\hline Lab-4 & 20 & $74.0 \%$ \\
\hline Lab-5 & 5 & $1.8 \%$ \\
\hline Lab-6 & 15 & $55.0 \%$ \\
\hline QueryComp & 3 & $1.1 \%$ \\
\hline Kahoot-3 & 8 & $29.0 \%$ \\
\hline Lab-7 & 16 & $59.0 \%$ \\
\hline
\end{tabular}

edition. We can observe at a first glance that, in this experience, gamification seems to be a bit lesser effective than in the other course, because there were students who achieved the same final grade regardless of their participation. Therefore, we added the number of times the student had taken the subject at the top of each element of the graph. Now, we can appreciate that the gamification is more effective for the students in their first enrollment. Moreover, the Pearson correlation coefficient is 0.57 , which indicates that there exists a positive and direct relationship between the gamification activities and the students' performance.

As with the other course, we again performed a t-test significance analysis to study whether participation in gamification activities had a positive impact in the students' mark. To do so, we divided the students in two groups. The former corresponds to the students who obtained at least a $50 \%$ of the gamification points and the second group was composed of the students who did not reach this score. The first group of students had an average mark of 5.01 out of 10 (standard deviation of 0.93) and the second had an average mark of 3.77 out of 10 (standard deviation of 2.03). The $t$-test returned a $p$ value of .02 ( $p$ value lower than .05), so it can be concluded that there is a significant relationship between the performance of the students and their participation in the gamification process. In addition, the percentage of passed students in the first group of the students who actively participated in the gamification activities was 
Final mark vs Gamification points- ISD

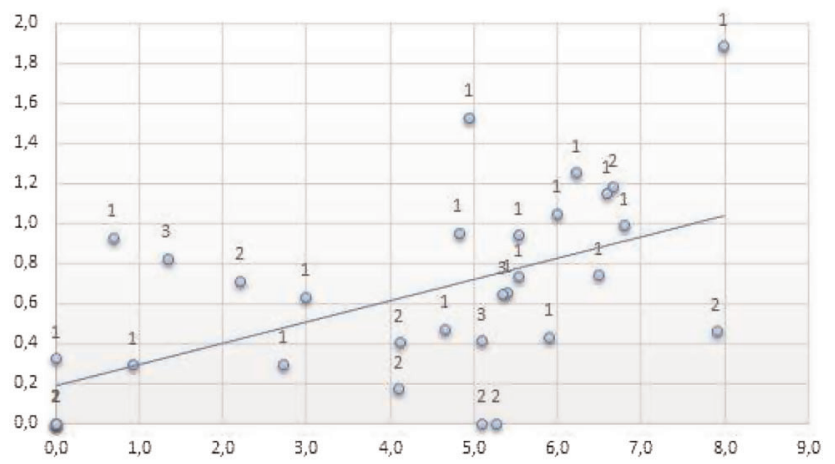

F I G URE 6 Dispersion diagram showing the correlation between gamification activities and the final mark in the ISD subject in the 2018-2019 academic year. The number on top of the dots indicates the enrollment number in the subject, for example, a 1 corresponds to a new student, whereas a 2 indicates that it is the second time that the student is taking the subject

$87.50 \%$ and it was $52.64 \%$ in the second group, a fact that reinforces this conclusion.

Following the same steps as for the DB subject, we executed a k-means algorithm on these data and found four learners' profiles according to their dedication level. Table 8 displays the four clusters.

It can be observed that Cluster_1 comprises the Achievers students, which implies that students made a higher effort than the average in all gamified activities and, consequently, obtained a final mark in the course notably higher than the rest. They are also the only students who completed the competition activity. Cluster_3 collects the Regular. These are characterized by having a participation with a higher intensity than the average, but lower than the Achievers. Also, we find the Disheartened learners, with a low participation in the gamified activities and a mark near or even lower than the average. Finally, the Underachievers students are located in Cluster_4, with a very low mark and also a low participation in the gamification. One fact to be remarked of the Underachievers students is that they obtained a high score in some concrete gamification activity, similar to kahoot. However, they had the lowest score in the labs activity. This fact points out that labs activity had an important weight in the learning goals.

\section{3 | Effect of the gamification on learners' performance}

Next, we show the evolution of the percentage of passed students for both subjects, DB and ISD, in Figure 7, with the aim of drawing attention to the effect of gamification on the learners' performance improvement. This includes three academic years. In the first one, 16-17, the subjects were taught without applying any gamification strategy. The following two academic years are the ones explained in detail in this paper.

Regarding DB subject, it can be observed that there is a slight growth in the percentage of passed students. It is true that the margin of improvement in this subject is lower than in ISD due to the high ratio of passed learners. However, the effect is higher in ISD with an increase of 5.03 percentage points from 16 to 17 to 17 to 18 and 8.89 from 17 to 18 to 18 to 19 , when the gamification activities were refined and extended. The global improvement in ISD is of 14.83 percentage points, which allow us to conclude that gamification can have a positive impact on the learning processes of the students. Nonetheless, given the low number of students enrolled in ISD, significance test like chi-square cannot confirm that the difference in percentage of passed students is significant, so these conclusions should be taken cautiously.

\section{4 | Student's opinion survey}

A survey was designed to collect students' opinion. This survey was comprised of eight questions, which were rated on a Likert scale of 1 (strongly disagree) to 5 (deeply
TABLE 8 K-means clustering performed with points achieved in the gamified activities and the final mark in ISD subject in the $2018 / 2019$ academic year

\begin{tabular}{|c|c|c|c|c|c|}
\hline Cluster & Cluster_1 & Cluster_2 & Cluster_3 & Cluster_4 & \\
\hline$\%$ of students & 18 & 53 & 18 & 11 & Average \\
\hline labs & 0.7352 & 0.329 & 0.5888 & 0.324 & 0.4313 \\
\hline design & 0.7576 & 0.1152 & 0.2576 & 0.5152 & 0.2626 \\
\hline kahoot & 0.9492 & 0.023 & 0.7373 & 0.8173 & 0.3729 \\
\hline competition & 0.5909 & 0 & 0 & 0 & 0.0657 \\
\hline total & 0.8127 & 0.2268 & 0.5592 & 0.4213 & 0.3874 \\
\hline mark & 6.5362 & 4.303 & 5.301 & 1.225 & 4.4309 \\
\hline
\end{tabular}




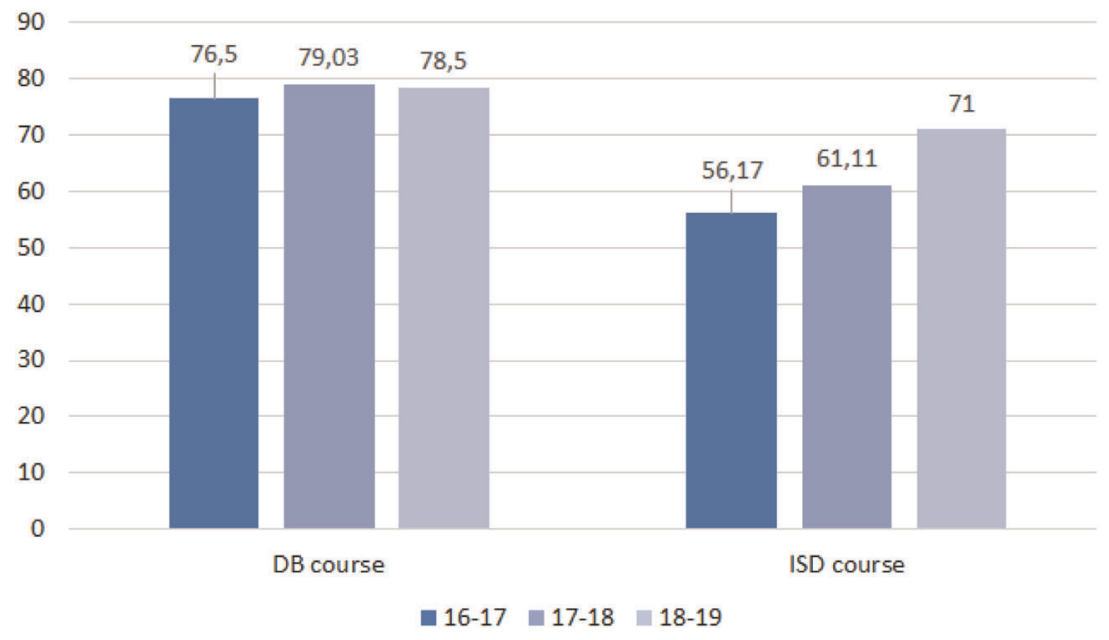

FIGURE 7 Evolution of the percentage of passed students in the last three years in ISD and DB courses

agree), except for the last two. Questions 7 and 8 allowed multiple selection and submitting brief open answers.

The questions were the following:

Q1. The gamification helped/motivated me to work on the content of the subject weekly

Q2. The gamification changed my study pattern, that is, now I work weekly and not exclusively by deadline dates

Q3. The forum messages are enough to inform me about the opening and closing of activities

Q4. The rating I give to the diversity of activities and, particularly, to the gamification system is ...

Q5. I consider that the number and type of activities, on average, one per week approximately, is adequate

Q6. I would have participated in the same way in the gamification activities even if they had not contributed to the final mark

The two semi-opened questions were as follows:

Q7. Point out the negative aspects you found in this experience:

7.1. It consumes a lot of time (if yes, indicate hours per week approx.)

Hours:

7.2. It limits the progress in other subjects of the semester

7.3. It is not worth spending time, and it is enough with classroom and laboratory activities

7.4. The tests do not motivate and you become disengaged

7.5. The process is not clear and you cannot organize your time

Others (indicate):

Q8. Point out the positive aspects you found in this experience:

8.1. It helps you study and keeps the subject updo-date
8.2. Feedback is helpful for progress in the subject

8.3. The progressive achievement of points motivates to continue studying

8.4. The hours spent reviewing and studying before the tests are fewer

8.5. You feel you master the subject (a deeper knowledge)

Others (indicate):

The survey was filled by 48 out of 62 DB students and 23 out of 28 ISD students in the 2018/2019 academic year, and by 52 out of 62 and 20 out of 31 students in the 2017/2018 academic year, respectively. Figures 8 and 9 show stacked bar charts with the percentages of respondents who answered each statement according to their level of agreement for each subject and academic year, respectively.

Observing Q1, we cannot say which gamification strategy is more effective. Whereas $57.90 \%$ of ISD students (summing 4 and 5 levels of agreement) in 17/18 academic year said that leaderboard strategy motivated themselves to study, their colleagues in 18/19 reduced the degree of agreement to $40.00 \%$. On the contrary, database learners in 17/18 did not consider that the strategy based on medals was enough to encourage them to work on the contents of the subject, whereas learners in 18/19 academic year strongly agreed with the statement $(64,45 \%)$, a fact that is supported by the Wilcoxon test, which returns a p-value lesser than 0.01 when the answers are compared with the mid-point of the scale, 3 . However, it is true that the latter edition included more types of gamification activities. This fact is endorsed by means of a t-test whose result yields a $p$-value lesser than 0.01 when comparing the average score of responses given in Q1 in 18/19, with a value of 3.9 out of 5 and standard deviation of 0.97 , with respect to $17 / 18$, with an average value of 2.76 with standard deviation of 1.18 . 
FI G URE 8 Percentages of learners who answered each statement according to their level of agreement in the subject of Databases in the $18 / 19$ academic year and, at the bottom, those corresponding to the $17 / 18$ academic year
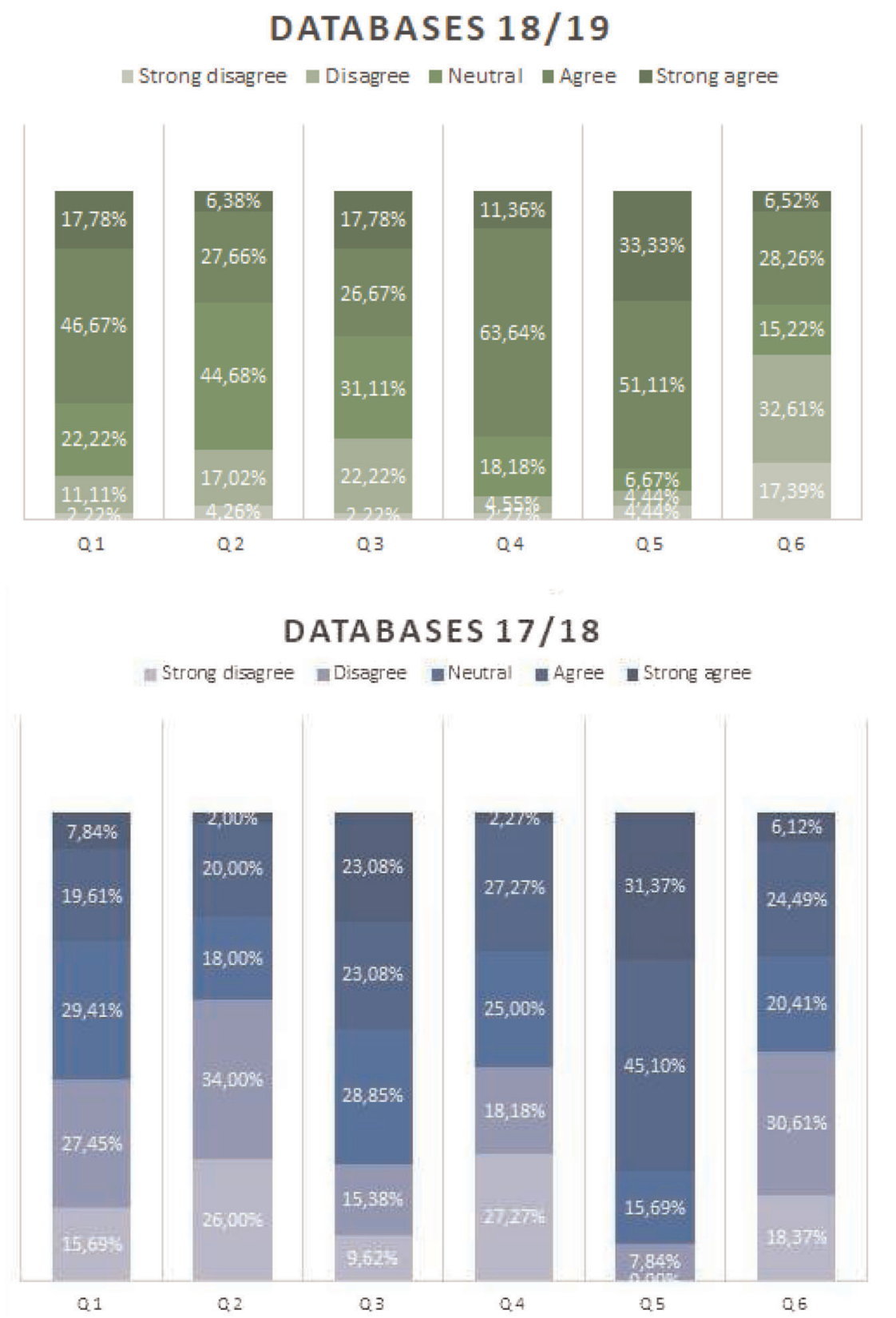

Regarding Q2, the percentage of students who recognized that the gamification led them to change their study pattern range between $15 \%$ and $34 \%$, being the neutral group very extent, around $40 \%$. The Wilcoxon test confirms that the answers are around the mid-point. It is remarkable that the leaderboard strategy got worse results. Probably, the labs were very demanding and, as mentioned previously, these students were enrolled in other hard subjects, so that they did not find time to manage all duties. In this case, the $t$-test also confirms that there is a significant difference ( $p$ value $<0.01$ ) when comparing the average score of responses given in Q2 in $18 / 19$, with a value of 3.17 out of 5 and standard deviation of 0.93 , with respect to $17 / 18$, with an average value of 2.38 with standard deviation of 1.14.

ISD students consider that the number of messages informing about the opening of activities and progress in the gamification was suitable to keep the participation active (above 63\%), whereas only around $45 \%$ of DB learners agree with the statement. The diversity of activities was sufficient to make the gamification attractive in both courses (above 60\%) in 18/19. It can be observed that gamification based on medals exclusively was considered poor (29.5\%). Likewise, they strongly agree with the number of one activity per week on average (Q5) with a percentage range between $60 \%$ and $84.44 \%$. 
INFORMATION SYSTEMS

DEVELOPMENT 18/19

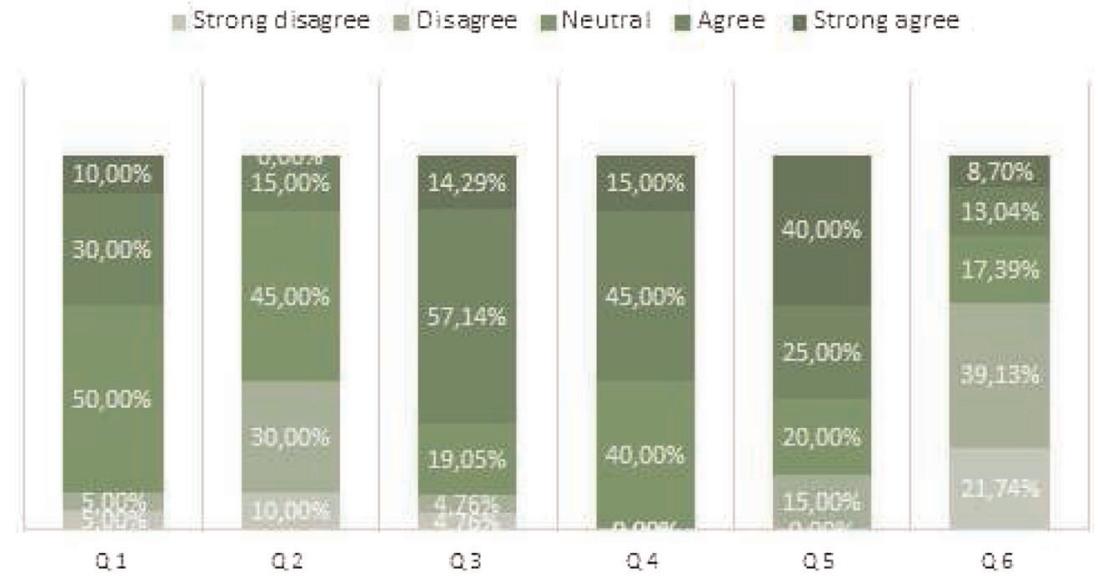

INFORMATION SYSTEM DEVELOPMENT $17 / 18$

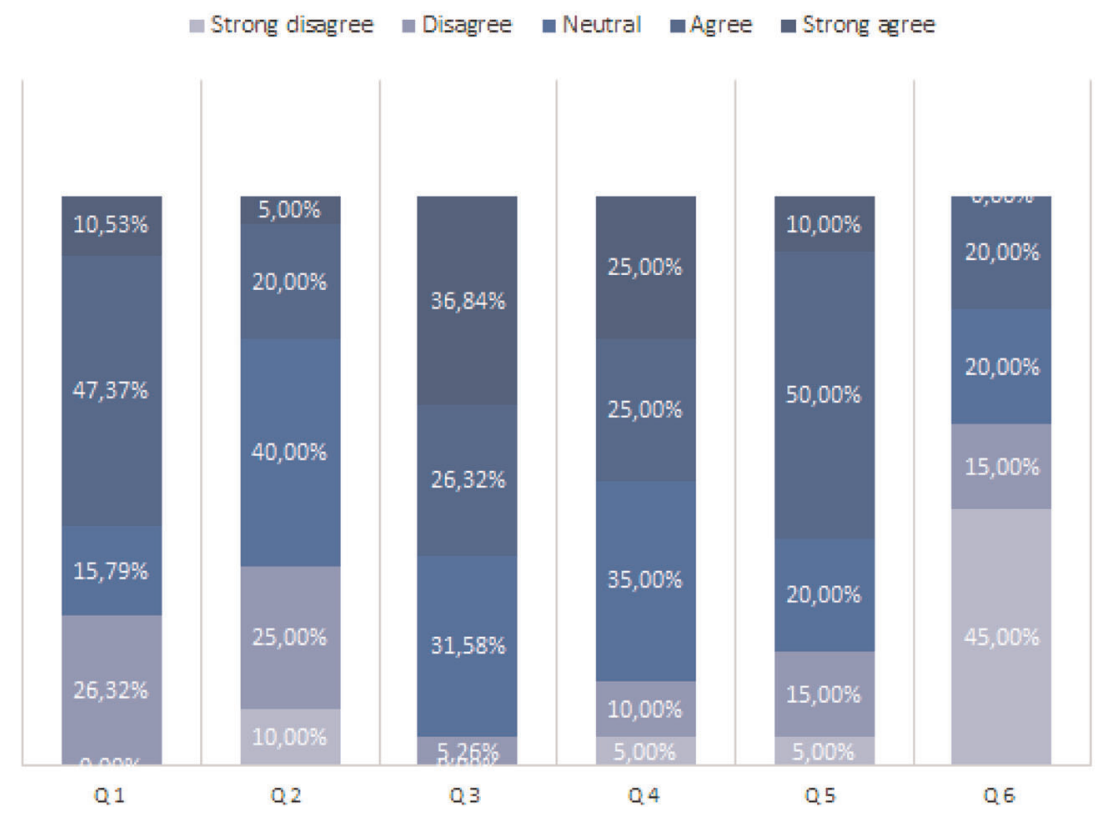

F I G URE 9 Percentages of learners who answered each statement according to their level of agreement in the subject Information Systems Development (top right) in the 18/19 academic year and, at the bottom, those corresponding to the $17 / 18$ academic year
In relation to its contribution in the final mark (Q6), most learners consider that this motivates them to complete it. The degree of disagreement ranges from $48 \%$ to $60.97 \%$.

It should be noted that questions Q1 to Q6 of the surveys of the two academic courses were the same, but for the last course, questions 7 and 8 were substituted to explicitly collect the positive and negative aspects that they found in the experience, which are analyzed next.

Table 9 presents the number of students who marked the options given in questions 7 and 8 in DB and ISD, respectively. The first fact to highlight is that there is a greater number of positive than negative responses, which might indicate that the gamification was interesting for the students and that helped them to advance in the subject and keep active. The 8.1 option (i.e., Gamification Helps studying and keeping updated) was marked by $77 \%$ of the database students. At a lesser extent, the gamification was positive for feedback. Also, $40 \%$ of the students indicated that the rewards motivated them to study. In relation to the negative aspects, only about $15 \%$ indicated that the activity hinders the progress in other subjects, and $22 \%$ could have been disengaged because the activities were not attractive enough; however, this contradicts the assessment given by them in Q4. Only three learners marked a value less than 3 out of 5 points.

Regarding ISD, half of the students considered that the gamification was useful and helped them being 
TABLE 9 Positive and negative issues selected by DB and ISD students related to the gamification activities

\begin{tabular}{|c|c|c|}
\hline Q7. Negative issues & DB & ISD \\
\hline 7.1. Consumes a lot of time & 4 & 6 \\
\hline 7.2. Limits progress in other subjects & 8 & 9 \\
\hline $\begin{array}{l}\text { 7.3. Not worth the time, compulsory activities are } \\
\text { enough }\end{array}$ & 5 & 2 \\
\hline 7.4. Tests are not motivating & 11 & 6 \\
\hline $\begin{array}{l}\text { 7.5. The process is not clear and it is difficult to } \\
\text { organize }\end{array}$ & 3 & 0 \\
\hline Q8. Positive issues & DB & ISD \\
\hline 8.1. Helps studying and keeping updated & 37 & 11 \\
\hline 8.2. Provides helpful feedback along the subject & 20 & 12 \\
\hline $\begin{array}{l}\text { 8.3. The progressive earning of points serves as } \\
\text { motivation }\end{array}$ & 19 & 6 \\
\hline $\begin{array}{l}\text { 8.4. Fewer hours of study required to prepare the } \\
\text { tests }\end{array}$ & 16 & 6 \\
\hline $\begin{array}{l}\text { 8.5. Gives a feeling of deeper knowledge in the } \\
\text { subject }\end{array}$ & 19 & 3 \\
\hline
\end{tabular}

up-to-date with the subject, but here $39 \%$ indicated that it hindered the progress of other subjects and $26 \%$ mentioned that the tasks were time-consuming. This is due to the completion of laboratories, which they had to complete for scoring. It must be said that the third-year students were enrolled in other three subjects that required a great effort, operating systems, communication networks, and computer architecture, so they could feel overwhelmed.

Due to the low frequency of the rest of negative issues, we consider that they are not sufficiently representative. None of students added another particular consideration.

\section{5 | Discussion}

To the best of authors' knowledge, there are a few recent works where gamification techniques were applied to foster outside class regular work. For instance, Huang et al. [12] applied them with the aim of improving the quality of flipped learning classrooms and [25] gamified in and out-of-class activities to research the effect of gamification built on leaderboards.

From the teachers' point of view, the gamification activities carried out in the experiences described in this paper had positive effects: the dynamics of the class improved and learners who were in class kept a more active attitude. We know that this is hardly verifiable, as we do not have instruments that allow us to measure behavioral and motivational issues. Therefore, the success of gamification is generally measured by the improvement of students' performance [8]. In this regard, we used data logs, students' final marks, and anonymous surveys filled by the learners.

After analyzing our evidence, we cannot confirm our first question (see Section 1) that the gamification favors extrinsic motivation and fosters the regular study. We thought that this depends on learners' cohort, their learning styles, and predisposition toward the game as well as the environment around them. Regrettably, we have no evidence to test this statement, but data show that the same experience in two consecutive academic years had different results. Furthermore, it can be observed that these strategies are not attractive for all students. We found two main causes: the first one is the fact that gamification was implemented in isolation from the rest of the subjects of the term; thus, the behavior change toward a pattern of continuous studying cannot happen uniformly. Second, students are adults and behavior changes at these ages are difficult to get and keep in time. Therefore, we consider gamification appropriate to apply it to noncompulsory activities in higher education. In literature, we found empirical studies that yielded positive results of the relationship between gamification and increase of levels of motivation and learners' engagement, as well as the existence of experiences with negative or mixed results, as pointed out Alsawaier in his review [2].

With regard to what strategy is more suitable for this purpose, our experience shows that although both were followed by the most of students, it is true that the strategy based on experience points and badges achieved a much higher participation rate by activity. The fact that these activities were not time-consuming could be the cause, but ISD students also had some short activities and the participation rate was also low. In our opinion, the workload of the rest of subjects influenced directly the development and success of the activity. Surprisingly, the SQL competition that we assumed was going to be very attractive had a low participation, probably due to the dates (last weeks of the course) in which it was held and also due to the time and effort that the activity required ( $1 \mathrm{~h}$ at maximum). In our experience, based on observing the dynamics of the students in class, the ranking strategy is only well received by a reduced number of learners (in the case of ISD subject, only one). In addition, those students do not to require to be gamified to achieve our purpose, as they belong to the Achievers group. Therefore, we considered that badges and experience points are more flexible and adaptable for engaging most students. This is endorsed by [4], which 
states that leaderboards show significant effects for performance but negative for motivation. Badges instead are superior for the feeling of competence but fell short in terms of performance.

Definitely, students consider that the gamification must be taken into account in the final grade to be attractive and followed by the most. They considered that their effort must be rewarded at a certain extent. In our proposal, this prize, that is, the points achieved by the gamified activities performed, helped students improve their final grade and reach a higher mark. It must be noted that the evaluation in these subjects is obtained as a weighting of several marks, and consequently, it is more complicated to get a high grade. In this way, achievers can reach the top, regular students are near the top, and the rest of learners can get a few tenths that allow them to pass the subject.

\section{6 | Limitations}

The results shown are conditioned by the participation of a reduced number of learners, near 90 per course. Most students (90\%) are male, with age ranging between 19 and 22 years, and are enrolled in a computer science degree; thus, they have skills in the use of technologies and they feel attracted to their utilization.

Due to both facts that the number of students in each subject is small and that the same conditions must be applied to all learners in the same terms as explained in the teaching guides, we could not have a control group, that is, a group of students that follows the subject, but that does not participate in the gamification activities, something that limits the contrast of hypotheses. Only those who did not achieve points in the final marks could be considered; however, the number is so reduced that their analysis was discarded due to their low statistical significance. Therefore, the definition of each group used in the t-test performed along the paper is explained in each section.

\section{5 | CONCLUSIONS}

This paper presents two experiences of gamification that aimed to foster learners to increase their study hours out of class. We followed two different strategies to adapt the gamification to the needs of each subject. The main selection criteria of these strategies were the number of learners enrolled in each subject and the effort (in time) required to give back feedback to the students during their progress. In the subject with a higher number of students and higher performance, we used badges and experience points that could be partially automated. In the other one, we designed the experience based on leaderboards, because the correction of labs and tasks required the review of an expert. The gamification was applied in two subjects about database topics in a computer science degree. The context and design of both implementations, as well as the resources used to carry them out, are described in this paper. Likewise, both experiences were analyzed from a qualitative and quantitative point of view. From this analysis, we draw the following conclusions:

- Ranking is well appreciated for achiever students, but these are, in general, a minority. Experience points and badges have a good acceptation for a wider number of learners according to students' participation in each type of activity. Furthermore, experience points allow satisfying at a certain extent the need of achievers of being at the top. Thus, we consider that a combination of badges and experience points offers more guarantees of being followed by more learners.

- Most learners prefer activities that involve few minutes to be solved, such as quizzes or Kahoot challenges, more than delivery of lab exercises or the participation in competitions.

- Awarding points in the final grade is positive to keep the gamification active during the term. However, this is not enough if there are other demanding tasks in parallel and/ or if the subject can be passed without its realization.

- Gamification organized by means of activities scheduled on certain dates may change learners' study patterns.

- Students who follow the gamification process obtain a higher performance than the students who do not. This fact could be explained as a consequence of the fact that they study the contents and train the skills that are essential in each subject.

In the future, the gamified activities of the ISD subject will be changed toward others that, pursuing the same objectives, require shorter completion times. Examples of these activities could be finding errors in conceptual designs, solving crosswords about database terminology, or evaluating the cost of already built queries in such a way that they review and work the learning outcomes without feeling overloaded. Regarding the SQL competition, we will plan its execution first, one or two weeks before to separate this from final exams to increase the number of participants. Finally, we will try to find two courses with a similar teaching guide with the aim of setting up a similar experiment with a control group, but without violating academic rules, to see if the results differ. 


\section{ACKNOWLEDGMENTS}

This study has been developed within the framework of a Teaching Innovation Project funded by the University of Cantabria. Authors also thank Miguel Ehécatl Morales Trujillo and Erick Orlando Matla Cruz, authors of the QueryCompetition tool [6], for their collaboration and support in the SQL competition performed in May 2019.

\section{DATA AVAILABILITY STATEMENT}

Data that support the findings of this study are available on request.

\section{ORCID}

Marta Elena Zorrilla Pantaleón (10) https://orcid.org/00000002-0475-8834

Diego García-Saiz (D) https://orcid.org/0000-0002-

7182-7879

Alfonso de la Vega (D) https://orcid.org/0000-0002-

7109-4249

\section{REFERENCES}

1. M. M. Alhammad and A. M. Moreno, Gamification in software engineering education: A systematic mapping, J. Syst. Softw. 141 (2018), 131-150.

2. R. S. Alsawaier, The effect of gamification on motivation and engagement, Int. J. Inf. Learn. Technol. 35 (2018), 56-79.

3. G. Barata, S. Gama, J. Jorge, and D. Gonçalves, Studying student differentiation in gamified education: A long-term study, Comput. Hum. Behav. 71 (2017), 550- 585.

4. P. Bräuer and A. Mazarakis, Badges or a leaderboard? how to gamify an augmented reality warehouse setting, Proceedings of the 3rd International GamiFIN Conference, Levi, Finland, April 8-10, 2019, volume 2359 of CEUR Workshop Proceedings (J. Koivisto and J. Hamari, eds.), CEUR-WS.org, 2019, pp. 229-240.

5. V. Cosentino, S. Gérard, and J. Cabot, A model-based approach to gamify the learning of modeling. Proceedings of the 5th Symposium on conceptual modeling education and the 2nd international iStar teaching workshop co-located with the 36th international conference on conceptual modeling (ER 2017), Valencia, Spain, November 6-9, 2017, pp. 15-24.

6. E. O. M. Cruz, M. E. M. Trujillo, and D. V. Portilla, 143 Querycompetition: Un sistema web para practicar consultas en sql, XXIII Jornadas sobre la Enseñanza Universitaria en Informática, vol. 1, AENUI, 2017, pp. 313-320.

7. S. Deterding, D. Dixon, R. Khaled, and L. Nacke, From game design elements to gamefulness: Defining "gamification", Proceedings of the 15th International Academic MindTrek Conference: Envisioning Future Media Environments, MindTrek '11, ACM, New York, NY, 2011, pp. 9-15.

8. D. Dicheva, K. Irwin, and C. Dichev, Exploring learners experience of gamified practicing: For learning or for fun? International Journal of Serious Games 6 (2019), no. 3, 5-21.

9. R. Elmasri and S. B. Navathe, Fundamentals of database systems (7th ed.), Pearson, New York, 2016.

10. European Higher Education Area. Ects users' guide, Technical Report, European Commission, 2015.
11. I. G. González, J. A. Moreno, I. N. Fructuoso, D. A. Juárez, S. S. Martos, and L. G. Ortiz, Design patterns to support gamification-based learning activities. In 1st Workshop on Gamification and Games for Learning, 2017.

12. B. Huang and K. F. Hew, Implementing a theory-driven gamification model in higher education flipped courses: Effects on out-of-class activity completion and quality of artifacts, Comput. Educ. 125 (2018), 254-272.

13. M. Jurgelaitis, L. Čeponiene, J. Čeponis, and V. Drungilas, Implementing gamification in a university-level UML modeling course: A case study, Comput. Appl. Eng. Educ. 27 (2019), no. 2, 332-343.

14. Y. k. Chou, Actionable gamification: Beyond points, badges, and leaderboards, Octalysis Media, Birmingham, UK, 2015.

15. J. Koivisto, J. Hamari. The rise of motivational information systems: A review of gamification research, International Journal of Information Management. 45(2019), 191-210. https://doi.org/10.1016/j.ijinfomgt.2018.10.013

16. E. Kyndt, I. Berghmans, F. Dochy, and L. Bulckens, 'time is not enough.' workload in higher education: A student perspective, High. Educ. Res. Dev. 33 (2014), no. 4, 684-698.

17. A. Marczewski, Gamification: A simple introduction and a bit more, Amazon Digital Services, Inc., Seattle, WA, United States, 2013.

18. A. Marczewski, Gamification: Even ninja monkeys like to play, Unicorn Editions Publishing Llc., 2018.

19. A. Mora, E. Planas, and J. A. Moreno, Designing game-like activities to engage adult learners in higher education. Proceedings of the Fourth International Conference on Technological Ecosystems for Enhancing Multiculturality, TEEM '16, ACM New York, NY, 2016, pp. 755-762. https://dl.acm.org/ doi/10.1145/3012430.3012603

20. A. Mora, D. Riera, C. S. G. González, and J. A. Moreno, Gamification: A systematic review of design frameworks, J. Comput. High. Educ. (2017), no. 1, 516-548.

21. A. Mora, G. F. Tondello, L. Calvet, C. S. González-González, J. A. Moreno, and L. E. Nacke, The quest for a better tailoring of gameful design: An analysis of player type preferences, Interacción '19, 2019. https://doi.org/10.1145/3335595.3335625

22. E. Nosair and H. Hamdy, Total student workload: Implications of the european credit transfer and accumulation system for an integrated, problem-based medical curriculum, Health Prof. Educ. 3 (2017), no. 2, 99-107.

23. M. Papastergiou, Digital game-based learning in high school computer science education: Impact on educational effectiveness and student motivation, Comput. Educ. 52 (2009), no. 1, 1-12.

24. O. Pedreira, F. García, N. Brisaboa, and M. Piattini, Gamification in software engineering-A systematic mapping, Inf. Softw. Technol. 57 (2015), no. 1, 157-168.

25. M. O. Rojas, K. Chiluiza, and M. Valcke, Gamification through leaderboards: An empirical study in engineering education, Comput. Appl. Eng. Educ. 27 (2019), no. 4, 777-788.

26. M. Sailer, J. U. Hense, S. K. Mayr, and H. Mandl, How gamification motivates: An experimental study of the effects of specific game design elements on psychological need satisfaction, Comput. Hum. Behav. 69 (2017), 371-380.

27. A. Silberschatz, H. F. Korth, and S. Sudarshan, Database system concepts (7th ed.), McGraw-Hill, New York, 2019. 
28. S. Subhash and E. A. Cudney, Gamified learning in higher education: A systematic review of the literature, Comput. Hum. Behav. 87 (2018), 192-206.

29. J. Swacha and K. Muszyńska, Design patterns for gamification of work. Proceedings of the Fourth International Conference on Technological Ecosystems for Enhancing Multiculturality. TEEM '16, ACM New York, NY, 2016, pp. 763-769. https://dl. acm.org/doi/10.1145/3012430.3012604

30. G. Lampropoulos T. Anastasiadis, and K. Siakas, Digital gamebased learning and serious games in education, Int. J. Adv. Sci. Res. Eng. 4 (2018), no. 12, 139-144.

31. J.-C. Woo, Digital game-based learning supports student motivation, cognitive success, and performance outcomes, Journal of Educational Technology \& Society 17 (2014), no. 3, 291-307.

\section{AUTHOR BIOGRAPHIES}

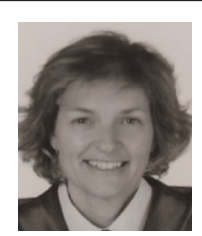

Marta Elena Zorrilla Pantaleón is an Associate Professor in Computer Science within Software Engineering and Real Time Group at the University of Cantabria (Spain). She has been involved in several national and European research projects together with other international research institutions. Her research interests are database technologies, data mining, and big data. She is also involved in different educational innovation projects and supervised one $\mathrm{PhD}$ thesis in educational data mining. She is the author of a database book and more than 60 works published in international journals, chapters, and conferences.

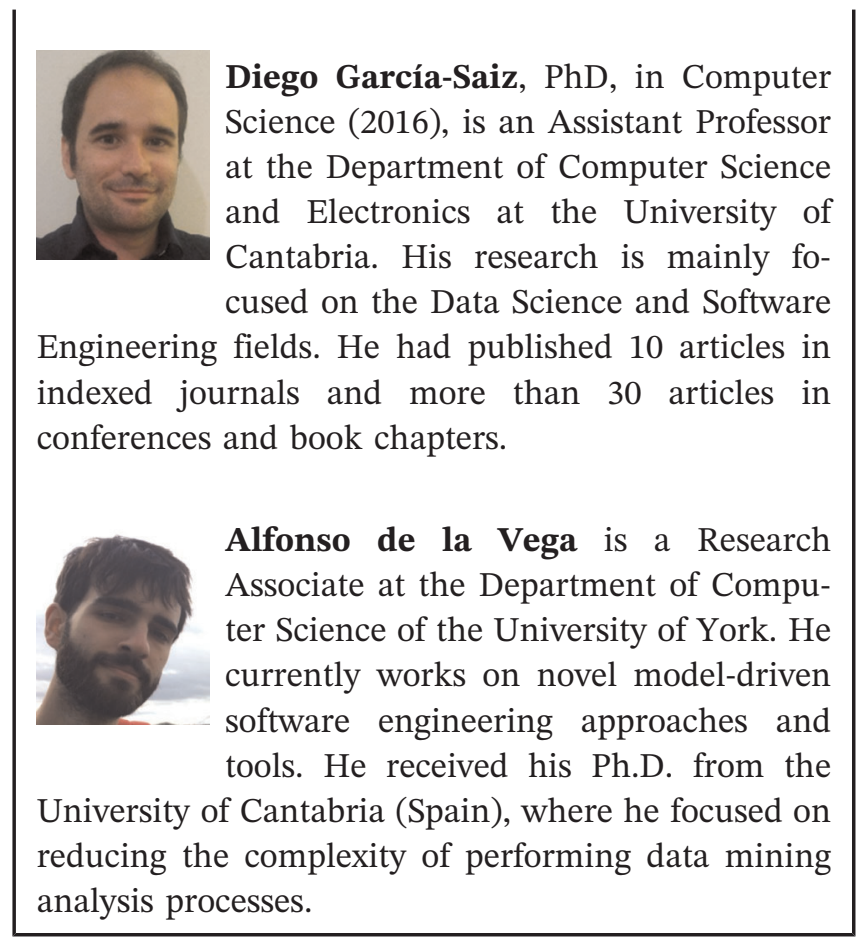

How to cite this article: Zorrilla Pantaleón ME, García-Saiz D, de la Vega A. Fostering study time outside class using gamification strategies: An experimental study at tertiary-level database courses. Comput Appl Eng Educ. 2021;1-18. https://doi.org/10.1002/cae.22389 